\title{
Double Myxopapillary Ependymomas of the Filum Terminale
}

\author{
Nancy McLaughlin, Marie-Christine Guiot, Line Jacques
}

Can. J. Neurol. Sci. 2011; 38: 151-154

Myxopapillary ependymomas (MPE) are benign spinal intradural tumors (WHO grade I) that characteristically occur in the conus medullaris/filum terminale region. They are slow growing tumors with a good prognosis and long-term survival. ${ }^{1}$ We report a rare case of double MPE occurring at both extremities of the filum terminale. In the light of the present case and an extensive review of the literature, we summarize the imaging characteristics and intra-operative findings that should be present when considering the diagnosis of double MPE. Knowledge of this entity should remind recall physicians to assess in detail the entire region of the conus medullaris/filum terminale to prevent missing the diagnosis of a second MPE. This is important since the surgical treatment should address both lesions.

\section{Case Report}

A 28-year-old man previously in good health presented with a severe lower back pain that had increased over the last two months. The questionnaire was negative for lower extremity paresthesia or paresia, for voiding difficulty and for sexual dysfunction. Complete neurological examination was normal the cervical and thoracic regions failed to show any other lesions or abnormal signals suggestive of dissemination. Also brain imaging was normal. The pre-operative diagnosis of both lesions was MPE.

The lesions were approached through a L2 laminotomy and L3 to S2 laminectomy. After opening the dura, both lesions appeared well encapsulated and isolated from one another (Figure 1, G\&H). Both lesions' capsule was intact, with no signs of previous rupture or diffuse growth on the nerve roots of the cauda equina. The filum terminale was macroscopically inspected and seemed of normal size and shape between both lesions. For the most rostral lesion, an en bloc excision was performed. The cauda equina lesion was partially removed given the dense adherences with the lumbosacral roots. Intra-operative preliminary report stated both lesions were identical MPE.

The definitive pathological assessment for both lesions showed tumor cells arranged in a papillary pattern around vascular areas, forming pseudorosettes, as well as large regions of mucoid degeneration. The immunohistochemistry for glial fibrillary acidic protein was strongly positive in both lesions. Cytokeratine (AE1/AE3) was mainly negative. MIB-1 was less

Table: Summary of double myxopapillary ependymomas of the filum terminale

\begin{tabular}{l|l|l|l|l}
\hline Author, Year & Sex, Age & Clinical symptoms & $\begin{array}{l}\text { Neurological } \\
\text { examination }\end{array}$ & Imaging finding \\
\hline $\begin{array}{l}\text { Gelabert-Gonzalez, } \\
2001\end{array}$ & F, 15 & $\begin{array}{l}\text { Lower back pain for 2 months, } \\
\text { with irradiation to left LE }\end{array}$ & $\begin{array}{l}\text { No focal defect } \\
\text { Positive Lasèque }\end{array}$ & Two lesions: L2-L3 and S3 \\
\hline Hallacq, 2003 & M, 13 & $\begin{array}{l}\text { Lower back pain for 5 months, } \\
\text { with irradiation in both LE }\end{array}$ & $\begin{array}{l}\text { No focal defect } \\
\text { Positive Lasèque }\end{array}$ & Two lesions: L1-L2 and S2-S3 \\
\hline Nakama, 2005 & M, 7 & $\begin{array}{l}\text { Lower back pain for 6 months, } \\
\text { dyuria for 3 months }\end{array}$ & No focal defect & Two lesions: L2-L3 and S2 \\
\hline Present case & M, 28 & Lower back pain for 2 months & No focal defect & Two lesions: L3-L4 and L5-S2 \\
\hline
\end{tabular}

including perianal sensation and rectal tone. Lumbosacral magnetic resonance imaging (MRI) revealed two isolated intradural lesions. The most rostral lesion located at L3-L4 measured $2.5 \mathrm{~cm}$ in its longest axis. The second, extending from L5-S2, measured $6.6 \mathrm{~cm}$ in its longest axis. Both lesions were heterogeneous in $\mathrm{T} 1$ and $\mathrm{T} 2$ and strongly enhanced after gadolinium injection (Figure 1, A-F). Complementary MRI of
From the Neuroscience Institute \& Brain Tumor Center (NM), John Wayne Cancer Institute at Saint John's Health Center, Santa Monica, California, USA; Department of Pathology (MCG), Department of Neurosurgery (LJ, NM), Montreal Neurological Hospital, Montreal, Quebec, Canada.

Received January 13, 2010. Final Revisions Submitted July 30, 2010. Correspondence to: Line Jacques, Montreal Neurological Hospital - McGill University, 3801 University Street, Montreal, Quebec, H3A 2B4, Canada. 


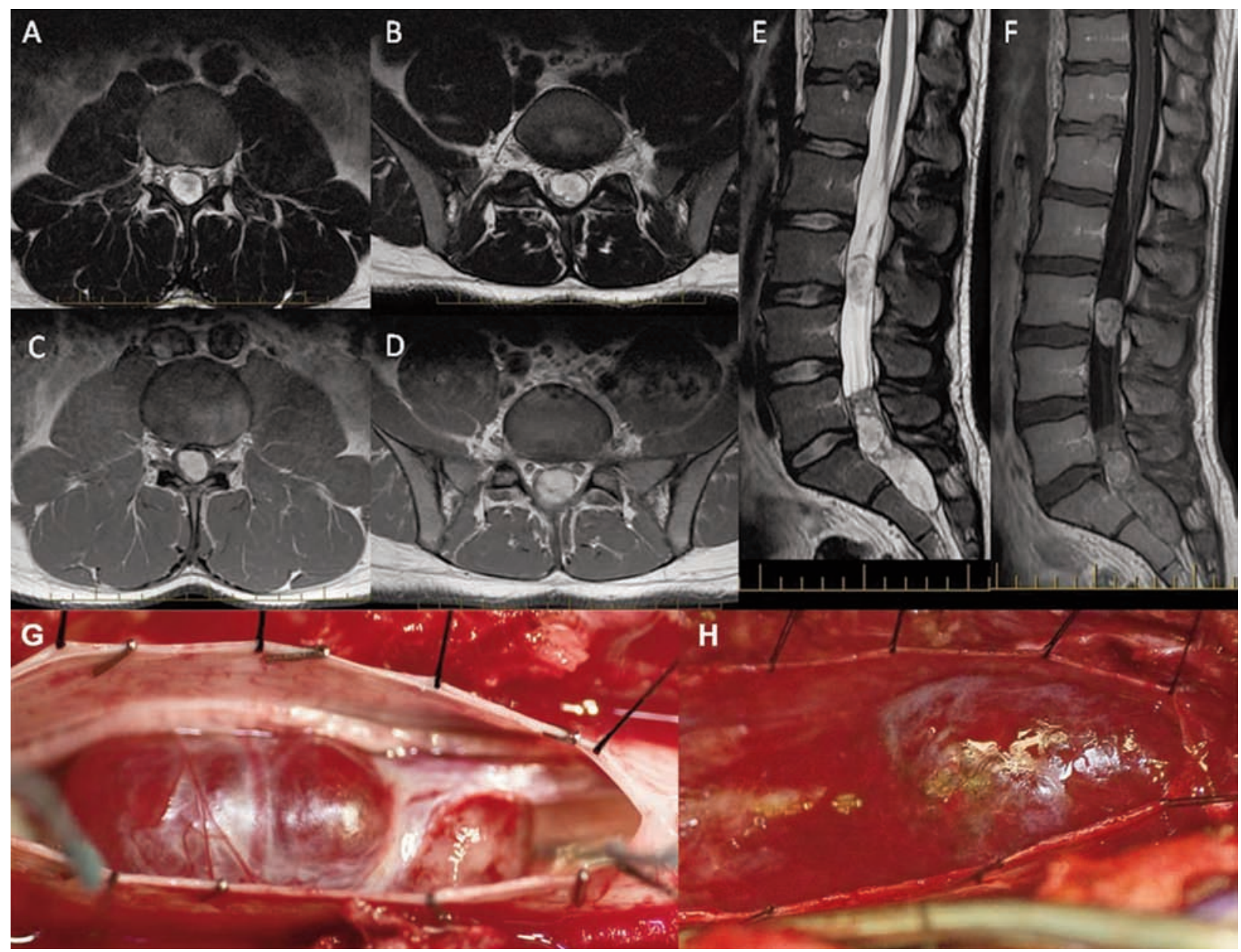

Figure 1: Pre-operative magnetic resonance imaging of the lumbosacral region (A to F). Axial T2 through the upper (A) and lower lesion (B); Axial T1 post-gadolinium through the upper $(C)$ and lower lesion (D); Sagital T2 $(E)$ and T1 post-gadolinium $(F)$; Intra-operative view of upper lesion $(G)$ and lower lesion $(H)$. The most rostal lesion located at L3-L4 was isolated from the second one found at L5-S2.

than $2-3 \%$ throughout the specimens both tumors. Both lesions were identical and characteristic of MPE.

Post-operatively, the patient had a favorable evolution with significant improvement of his lower back pain. No focal deficit was documented at follow-up examination. Immediate postoperative MRI confirmed complete resection of the most rostral lesion and partial removal of the distal lesion (Figure 2). No lumbar puncture was performed pre- or post-operatively given the good quality pre-operative craniospinal MRIs that showed no evidence of leptomeningeal dissemination. The patient underwent focal conventional radiotherapy treatment in the cauda equina region for local control of the partially removed MPE. Presently 11 months after surgery and radiation therapy, the patient remains clinically and radiologically disease-free.

\section{DISCUSSION}

Approximately $40-80 \%$ of ependymomas of the filum terminale and the conus medullaris region are MPE. These spinal intradural tumors are benign, classified as grade 1 according to the WHO. Although they most frequently occur as solitary lesions, they may rarely present as two synchronous lesions located at both extremities of the filum terminale..$^{2-4}$ A review of the English literature identified only three other cases diagnosed specifically as double MPE of the filum terminale without any evidence of subarachnoid dissemination along the craniospinal axis (Table $)^{2-4}$. As in the present case, lower back pain was present only a few months before diagnosis in all cases. Furthermore, other than a positive Lasèque sign in two cases, no focal deficit was found pre-operatively.

When two independent lesions present at the upper and lower part of the terminal filum, one may question if both lesions are synchronous bifocal lesions or if they represent spreading along a continuum. In all reported cases including the present patient, pre-operative imaging and intra-operative findings documented two well circumscribed lesions at both extremities of the filum terminale. No evidence of dissemination was found on preoperative imaging and during intra-operative macroscopic inspection in all cases. Furthermore, in the case reported by 


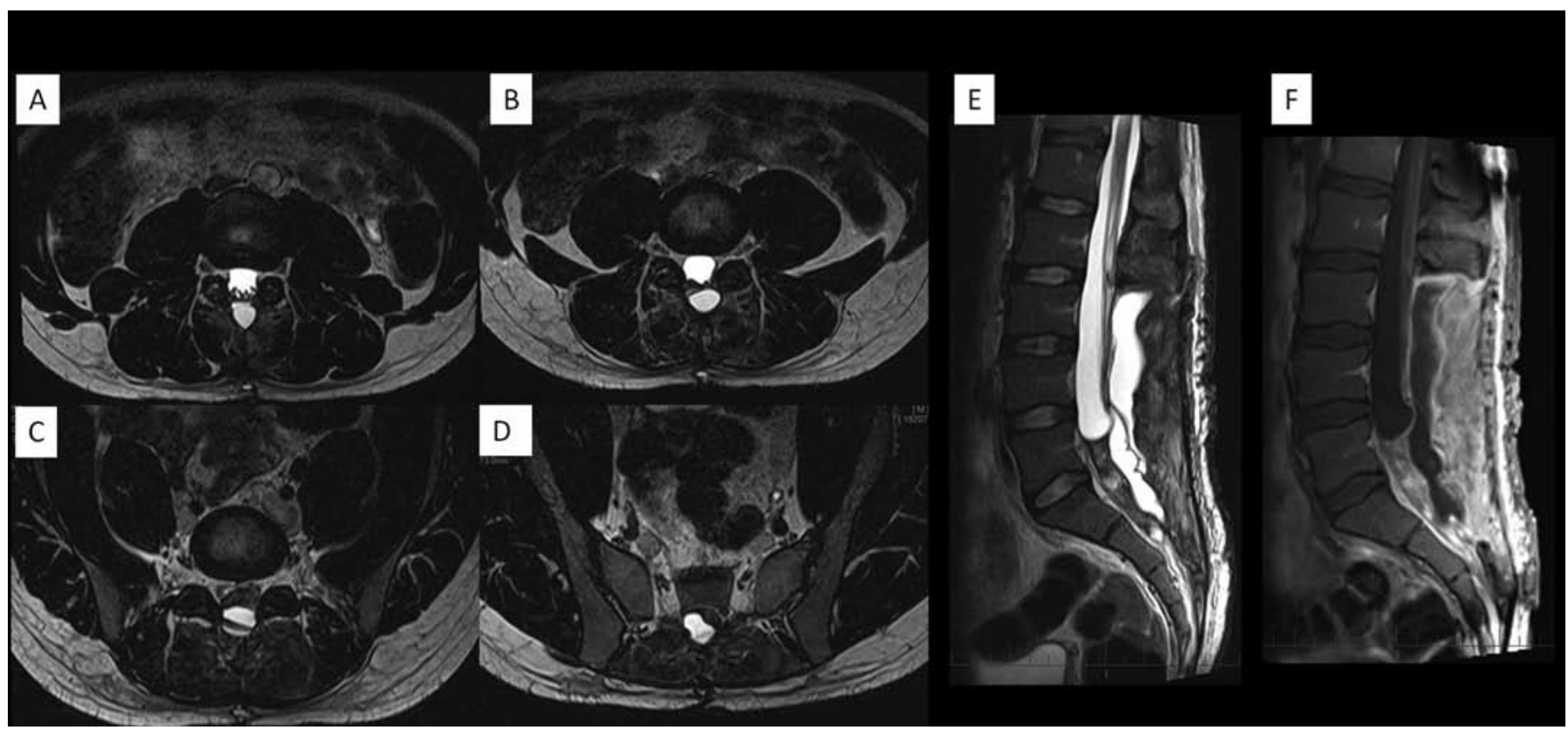

Figure 2: Post-operative magnetic resonance imaging of the lumbosacral region (A to F). Axial T2 through L3-L4 (A), L4-L5 (B), L5-S1 (C), and S1$S 2(D)$. Sagital T2 (E) and T1 post-gadolinium $(F)$. Gross total resection of the most rostral lesion (L3-L4) and partial removal of the second lesion found at L5-S2.

Hallacq and colleagues, repeated pathology examination was performed and confirmed the absence of tumor tissue within the terminal filum between both lesions ${ }^{2}$. Given these imaging, macroscopic and microscopic findings, authors of previous cases of double MPE have concluded that these were independent lesions and not distant metastasis or dissemination along the neuraxis $^{2-4}$.

Although the molecular alterations leading to ependymomal oncogenesis are not completely understood, it has been recently demonstrated that ependymomas from different central nervous system regions have a distinct genetic and molecular signature ${ }^{5-6}$. We propose that patients with double MPE may potentially have an early genetic alteration in ependymal stem cells within filum terminale. The subsequent accumulation of different genetic alterations may explain the occurrence of two different lesions each harbouring a different genetic signature. When available, a genetic analysis of multiple tumor samples may be a key element to confirm the exact mechanism of development of multiple ependymomas. In the light of the present case and of the other reported cases, the following elements may help diagnose double MPE. Both lesions should be completely isolated from one another along the filum terminale. Pre-operatively, this should be assessed on MRI. Intra-operative findings should document two independent lesions with a macroscopically intact tumor capsule and normal appearing filum terminale. In addition, the absence of evidence of subarachnoid dissemination along the craniospinal axis should be assessed on pre- or postoperative MRI and/or on postoperative cerebral spinal fluid (CSF) cytology ${ }^{7-8}$. Definitive pathology should confirm that both tumors are identical regarding histology, immuno-histochemistry staining and mitotic index. If feasible, the filum terminale between both lesions should be examined histologicaly to rule-out the presence of tumoral islands within it $^{2}$. When available, genetic assessment may also be an important complement the work-up of double ependymomas $^{5-6}$

Given the anatomic complexity of the filum terminale and the cauda equina, MPE of this region may be challenging to completely remove. Large series report gross total removal in 43 to $59 \%$ of cases $^{9,10}$. In general, the prognosis of MPE is favourable with a median survival of 19 years following a gross total removal and 14 year following a subtotal removal ${ }^{11}$. However, long-term follow-up with serial imaging is essential since local tumor recurrence and leptomeningeal dissemination may occur. Despite gross total removal, tumors involving the filum terminale are more likely to recur than other locations with recurrence rates varying between $10-19 \%{ }^{1,9}$. Subtotally resected ependymomas have an even higher predilection for recurrence and/or dissemination achieving rates of $70 \%$ in series without any adjuvant treatment ${ }^{11,12}$. The use of adjacent radiation therapy following subtotal removal has achieved local control rates of $66-100 \%{ }^{12}$. Therefore, the extent of tumor resection as well as the MRI evaluation for leptomeningeal dissemination ultimately guides adjuvant therapies in the setting of these low grade spinal tumors. The present reported case received adjuvant conventional therapy to the region of the distal lesion that was partially resected but none to the conus site given gross total tumor removal. This is in accordance with the fact that radiation therapy for grossely removed MPE remains controversial.

In summary, knowledge of double MPE entity should incite physicians to specifically evaluate the entire filum terminale and prevent missing a second MPE. Pre-operative recognition of 
double MPE of the filum terminale is important since the surgical treatment should address both lesions.

\section{REFERENCES}

1. Bagley CA, Wilson S, Kothbauer KF, Bookland MJ, Epstein F, Jallo GI. Long term outcomes following surgical resection of myxopapillary ependymomas. Neurosurg Rev. 2009; 32:321-34.

2. Hallacq P, Labrousse F, Streichenberger N, Lisii D, Fischer G. Bifocal myxopapillary ependymoma of the terminal filum: the end of a spectrum? Case report. J Neurosurg. 2003;98:288-9.

3. Nakama S, Higashi T, Kimura A, Yamamuro K, Kikkawa I, Hoshino Y. Double myxopapillary ependymoma of the cauda equine. J Ortho Sci. 2005;10:543-5.

4. Gelabert-González M, Prieto-González A, Abdulkader-Nallib I, Cutrín-Prieto J. Double ependymoma of the fillum terminale. Childs Nerv Syst. 2001;17:106-8.

5. Rousseau A, Idbaih A, Ducray F, et al. Specific chromosomal imbalances as detected by array $\mathrm{CGH}$ in ependymomas in association with tumor location, histological subtype and grade. J Neurooncol. 2010;97:353-64.
6. Korshunov A, Neben K, Wrobel G, et al. Gene expression patterns in ependymomas correlate with tumor location, grade, and patient age. Am J Pathol. 2003;163:1721-7.

7. Fassett DR, Pingree J, Kestle JR. The high incidence of tumor dissemination in myxopapillary ependymoma in pediatric patients. Report of five cases and review of the literature. J Neurosurg. 2005;102:59-64.

8. Freilich RJ, Krol G, DeAngelis LM. Neuroimaging and cerebrospinal fluid cytology in the diagnosis of leptomeningeal metastasis. Ann Neurol. 1995;38:51-7.

9. Celli P, Cervoni L, Cantore G. Ependymoma of the filum terminale: treatment and prognostic factors in a series of 28 cases. Acta Neurochir (Wien). 1993;124:99-103.

10. Sonneland PR, Scheithauer BW, Onofrio BM. Myxopapillary ependymoma. A clinicopathologic and immunocytochemical study of 77 cases. Cancer. 1985;56:883-93.

11. Rezai AR, Woo HH, Lee M, Cohen H, Zagzag D, Epstein FJ. Disseminated ependymomas of the central nervous system. J Neurosurg. 1996;85:618-24.

12. Wahab SH, Simpson JR, Michalski JM, Mansur DB. Long term outcome with post-operative radiation therapy for spinal canal ependymoma. J Neurooncol. 2007 May;83(1):85-9. 